Editorial Manager(tm) for AIDS

Manuscript Draft

Manuscript Number: AIDS-D-05-01179R1

Title: CONTROVERSY CONCERNING ROLE OF ULTRASONOGRAPHIC LIPOATROPHY ASSESSMENTS IN HIV PATIENTS

Article Type: Correspondence

Section/Category:

Keywords: Ultrasonography; lipoatrophy; HIV infection; facial; fat

Corresponding Author: Dr rosario gulizia, MD

Corresponding Author's Institution: Division of Infectious and Tropical Disease

First Author: Rosario Gulizia, MD

Order of Authors: Rosario Gulizia, MD; Alessandro Vercelli, MD; Gervasoni

Cristina, MD; Massimiliano Ortu, MD; Giuliana Troia, MD; Fabrizio Calliada, PhD; Massimo Galli, PhD; Carlo Filice, PhD

Manuscript Region of Origin: 
Title page

CONTROVERSY CONCERNING ROLE OF ULTRASONOGRAPHIC

LIPOATROPHY ASSESSMENTS IN HIV PATIENTS

Short title

\section{ULTRASONOGRAPHY ASSESSMENTS OF LIPOATROPHY}

Gulizia R, Vercelli A*, Gervasoni $C^{\S}$, Massimiliano Ortu ${ }^{\S}$, Calliada F*, Troia G, Galli $\mathbf{M}^{\S}$ e Filice $\mathbf{C}$.

Division of Infectious and Tropical Diseases, IRCCS S Matteo, University of Pavia

* Istituto di Radiologia, IRCCS San Matteo, University of Pavia

$\S$ Infectious and Tropical Disease Institute, IRCCS L. Sacco, University of Milano

Rosario Gulizia, MD

Division of Infectious and Tropical Diseases

IRCCS S. Matteo University of Pavia School of Medicine

Viale Taramelli 5

27100 Pavia

tel +39382502887

e-mail: sargul@katamail.com

No. of words: 537 
To the Editor,

We read with interest the important contribution of Carey et al. to the debate concerning US lipodystrophy assessments. ${ }^{[1]}$

They excluded the possibility of using ultrasonography (US) to assess facial atrophy: in particular, they did not find a correlation with more established measures such as dualenergy X-ray absorptiometry (DEXA) and computed tomography (CT), or with subjective severity scores assessed by physical examination or patient reports. However, although the use of US in assessing lipodystrophy alterations has objective difficulties in terms of standardization, its accuracy in measuring changes in subcutaneous fat thickness (SFT) at brachial, crural and malar level has been demonstrated by Martinez et al. $^{[2]}$, Asensi et al. ${ }^{[3]}$ and ourselves. ${ }^{[4]}$

Carey et al. chose the outer canthus of the right eye and the upper margin defined by malar bone as their reference point for the US determination of malar SFT, and this deserves some comment because, in our opinion, the correct way to determine the size of Bichàt's bulla and measure malar SFT is to use a nasogenian transversal scan from the malar bone to the skin (Fig. 1).

The reasons for this choice also include the clinical presentation of sunken cheeks and, after a long debate and a number of practical attempts with our radiologists, we believe that our scan is more representative of facial atrophy than the longitudinal image taken by Carey et $a .^{[1]}$

Our reference point corresponds to the deepest point of Bichàt's bulla, which we think is the correct echographic reference point for measuring facial lipoatrophy whereas, in our 
experience, the topographical site used by Carey et al. is too peripheral to guarantee a realistic description of fat loss.

In addition to this crucial technical point, some other considerations need to be made.

We feel that the most important correlation in this kind of investigation is with the patient's body mass index (BMI) because subcutaneous and visceral fat distribution is related to the BMI in the majority of cases, with lipoatrophy when BMI $<27 \mathrm{~kg} / \mathrm{m}^{2}$ and lipohypertrophy when $\mathrm{BMI}>27 \mathrm{~kg} / \mathrm{m}^{2} \cdot{ }^{[5,6]}$ It is also well known that the presentation of lipodystrophy is often different in male and female HIV patients ${ }^{[7]}$, and there is still controversy concerning gender-related differences in body fat distribution. ${ }^{[8]}$

Comparing US and DEXA facial data is not necessarily appropriate because, by definition, DEXA cannot give any information about regional fat distribution and the simple DEXA evaluation of limb fat mass can be unreliable unless it is corrected by BMI. Similarly, attempts to correlate US determinations with CT scans of body regions other than the malar region carry the same risk of inaccuracy.

The lack of correlation between patient and doctor judgments and US determinations can be easily explained on the basis of the choice of the topographic reference point discussed above.

At the 5th International Workshop on Adverse Drug Reactions and Lipodystrophy in HIV (Paris, 2003), Milinkovic et al. ${ }^{[9]}$ reported a good correlation between US and CT or DEXA subcutaneous fat measurements at similar levels.

Although it has not yet been demonstrated that US can assess lipodystrophy, the possibility of at least partially replacing expensive methods of measuring fat alterations such as DEXA and $\mathrm{CT}$ is too important to be abandoned without further investigations. 


\section{References}

1. Carey D, Wand H, Martin A, et al. Evaluation of ultrasound for assessing facial lipoatrophy in a randomized, placebo-controlled trial. Aids 2005,19:1325-1327.

2. Martinez E, Bianchi L, Garcia-Viejo MA, Bru C, Gatell JM. Sonographic assessment of regional fat in HIV-1-infected people. Lancet 2000,356:1412-1413.

3. Asensi V, Martin-Roces E, Carton JA, et al. Perirenal fat diameter measured by echography could be an early predictor of lipodystrophy in HIV type 1-infected patients receiving highly active antiretroviral therapy. Clin Infect Dis 2004,39:240-247.

4. Gulizia R, Brunetti E, Gervasoni C, Galli M, Filice C. Sonographic assessment of lipodystrophy in HIV-infected patients: some open questions. Clin Infect Dis 2005,40:323324; author reply 324-325.

5. Muurahainen N, Pettit, R, Kotler, D, Falutz, J, Santos, G, Kleintop, M, Glesby, M, et al. Abnormalities in HIV-associated lipodystrophy syndrome that vary by weight status [Abstract 63]. In: 1st International Workshop on Adverse Drug Reactions and Lipodystrophy in HIV. Edited by 53. San Diego, CA; 1999.

6. Lichtenstein KA. Redefining Lipodystrophy Syndrome: Risks and Impact on Clinical Decision Making. Journal of Acquired Immune Deficiency Syndromes 2005,39:395-400.

7. Galli M, Veglia, F, Angarano, G, et al. Gender differences in antiretroviral drug-related adipose tissue alterations: women are at higher risk than men and develop particular lipodystrophy patterns. Journal Acquired Immune Deficiency Syndrome 2003,34:58-61.

8. Komiya S, Eto C, Otoki K, Teramoto K, Shimizu F, Shimamoto H. Gender differences in body fat of low- and high-body-mass children: relationship with body mass index. Eur $J$ Appl Physiol 2000,82:16-23.

9. Milinkovic A, Vidal S, Bianchi L, Ayuso C, Dominigo P, Gomila M, et. al. Comparative assessment of objective methods for the measurement of body fat. 5th International Workshop on Adverse Drug Reactions and Lipodystrophy in HIV. Paris, 8-11 July 2003. 
Figure 1- US “malar skin point” for measuring facial lipoatrophy 
Figure
Click here to download high resolution image

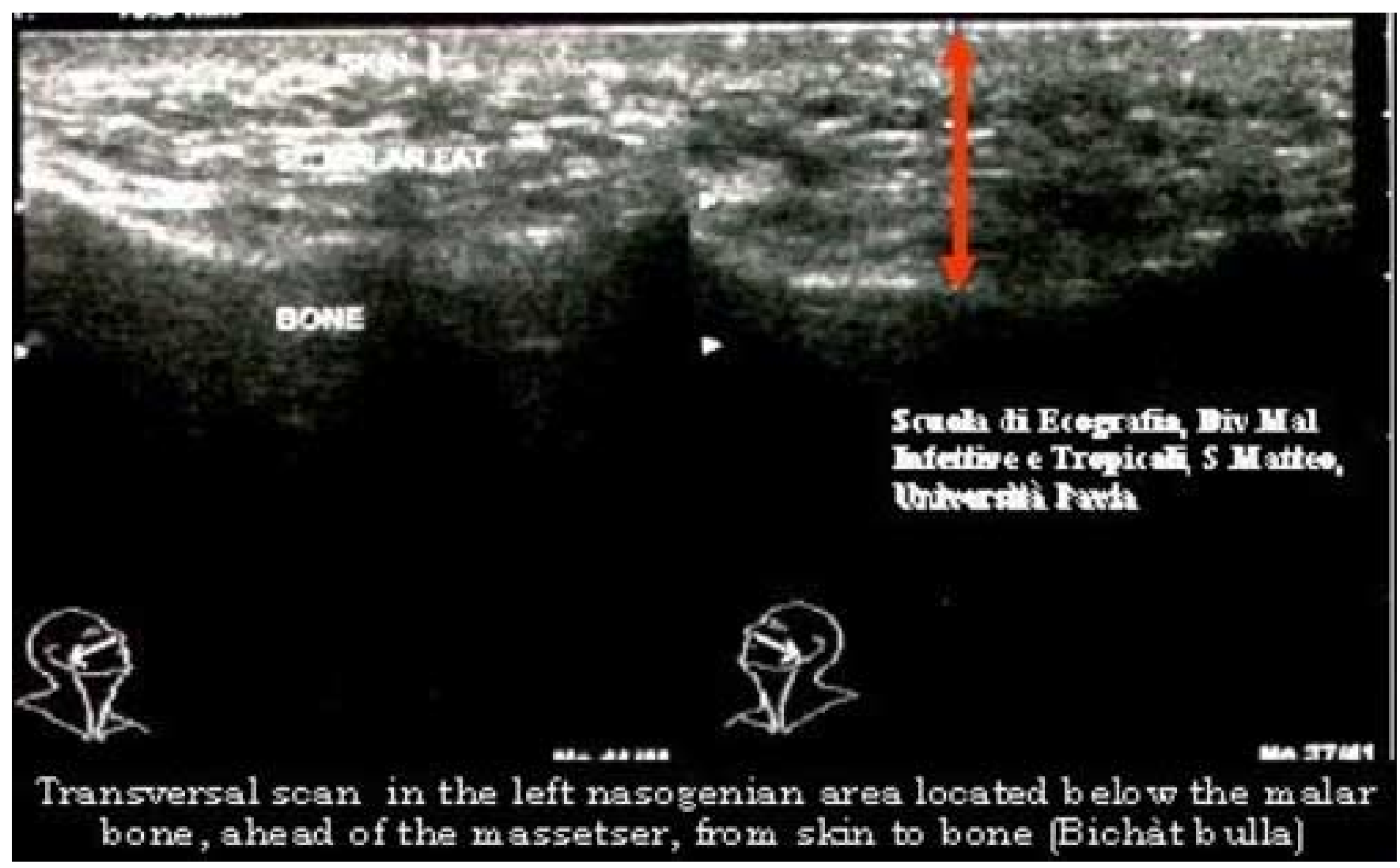

